\title{
A first approach to assessing soil oxygenation in the field using the Tensionic ceramic tensiometer
}

\author{
A Vigouroux* \\ Laboratoire de biologie et pathologie végétales, Ensa, Inra, 2, place Viala, 34060 Montpellier cedex 1, France
}

(Received 23 September 1996; accepted 15 December 1997)

\begin{abstract}
Summary - This paper describes a prototype method for assessing oxygen availability in soils using water injected into the ceramic cup of the Moutonnet Tensionic tensiometer. The water is recovered after several days of equilibration with the soil solution and the dissolved oxygen it contains is immediately measured with a field oxymeter. The easy installation, low cost of each device and rapid measurement allow numerous replications in the same plot, making it possible to obtain representative results. Certain metrological refinements are still needed, but the consistency of the results already obtained suggests that the device offers interesting possibilities in various areas of agronomic studies. (@ Inra/Elsevier)
\end{abstract}

soil / aeration / oxymeter / ceramic cup tensiometer

Résumé - Une tentative d'estimation commode de l'oxygénation des sols à l'aide du tensiomètre à bougie poreuse Tensionic. Il est décrit un principe d'estimation du niveau d'oxygénation des sols utilisant l'eau injectée dans la bougie du tensiomètre Tensionic de Moutonnet. Cette eau, après plusieurs jours de mise à l'équilibre avec la solution du sol, est récupérée et on y dose immédiatement l'oxygène dissous à l'aide d'un oxymètre de terrain. La facilité de pose, la modicité du prix de chaque appareil et la rapidité de la mesure autorisent un nombre important de répétitions par parcelle devant permettre d'obtenir des valeurs représentatives des conditions globales du sol exploré par les racines. Divers ajustements métrologiques sont encore nécessaires mais la cohérence des résultats déjà obtenus semble confirmer les possibilités intéressantes de ce système pour conforter divers types d'études agronomiques. (C Inra/Elsevier)

sol / aération / oxymètre / tensiomètre

\section{INTRODUCTION}

To analyse the mechanisms by which coarse-textured soils predispose stone fruit trees to certain bacterial diseases (Vigouroux and Bussi, 1994b), it was necessary to determine in what conditions tree roots function in winter. Matric potential and oxygenation could be critical factors and have to be assessed under field conditions. Matric potential is easy to measure but the different methods available for oxygenation are generally unwieldy and sometimes unreliable (see synthesis by Levy and Toutain, 1979; Glinsky and Stepniewski, 1985; or the paper by Faulkner et al, 1989). Other

\footnotetext{
* Correspondence and reprints

Tel: (33) 04996125 47; fax (33) 04675459 77; e-mail: vigouroux@ensam.inra.fr
} 
methods (Renault and Stengel, 1994) are devoted to extremely fine analyses and not adapted to providing a global estimation at the level of the horizon exploited by roots. An adapted use of the Tensionic, a ceramic tensiometer perfected by Moutonnet (Moutonnet et al, 1993), provided us with a series of values suggesting that this device might offer interesting possibilities for achieving this objective (Vigouroux and Bussi, 1994a). In this paper we simply describe the measurement principle involved and present a few results in order to draw attention to what might be a convenient and fairly inexpensive method of monitoring global soil oxygenation.

\section{MATERIALS AND METHODS}

\section{Principle}

Moutonnet's Tensionic (fig 1) is a modified tensiometer with a system of capillary tubes leading to the ceramic cup, which remains in place in the soil. Water is injected into the device and recovered about $10 \mathrm{~d}$ later, after equilibration with the soil solution by diffusion through a 'high-flow' ceramic cup. Moutonnet used the device to monitor nitrate levels in fertilised soils and groundwater, but it is obviously also possible to monitor a large number of other elements in the collected liquid sample, which can be considered as being relatively similar to the soil solution itself. If the dissolved oxygen in the solution is in equilibrium with the soil atmosphere, it should be possible, with a minimum of precautions, to estimate the oxygenation conditions available to roots by measuring the dissolved oxygen in the sample with an oxymeter.

\section{Description of the apparatus}

A porous ceramic cup with a sample volume of $12 \mathrm{~mL}$ is fixed to the end of a PVC tube of the same external diameter (approximately $25 \mathrm{~mm}$ ). Different lengths of tube are used so that the ceramic cup can be positioned at the required depth. A preliminary hole is dug with a special auger the size of the ceramic cup. In stony soil, it is often necessary to drive an iron rod the same size as the Tensionic into the ground. As with ordinary tensiometers, the usual precautions are taken to ensure a continuum between the soil and the ceramic cup and to isolate the latter from the direct effect of any free air around the outside of the tube. A capillary PVC tube (E) connects the top of the device and the bottom of the ceramic cup and is used to fill and empty the cup. A second capillary tube $(\mathrm{P})$ is connected at the top of the ceramic cup and is used to purge the system. A third tube (T) can be used in parallel to measure the soil water matric potential, if required.

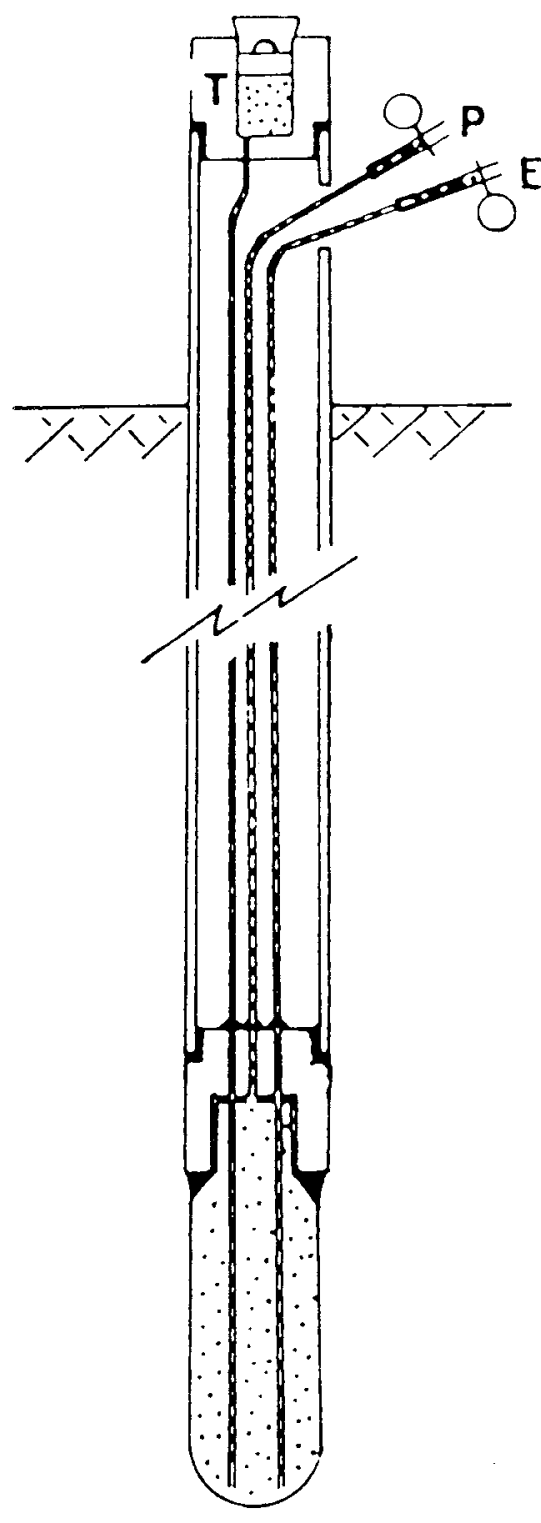

Fig 1. Simplified description of the Tensionic device (from Moutonnet et al, 1993). E: extraction tube; P: purge tube; T: tube used to measure matric pressure.

\section{Measurement of the dissolved oxygen}

Distilled water was used to improve standardisation. The ceramic cup was filled via the first tube by means of a syringe until the water overflowed via the purge tube, and the ends of the two tubes were then sealed. For monitoring nitrates, Moutonnet et al (1993) have established a 10-d equilibration time with the soil solution. Taking this as a minimum time $(12 \mathrm{~d}$ were used in practice), we extracted the liquid from the ceramic cup, still using a syringe and recovering only 12 of the $13 \mathrm{~mL}$ injected ( 12 in the ceramic cup +1 in the tubes) to ensure no bubbles were present at the end of the sam- 
pling. The liquid was then injected into a small narrownecked glass phial and into the bottom of the phial to reduce oxygenation of the sample by air to a minimum. An oxymeter probe was then slowly introduced and gently moved around to make the measurement. A WTW 0X 320-type oxymeter and a Cellox 325 probe were used, and the measurement stabilised after 40-50 $\mathrm{s}$. The oxymeter had a resolution of $0.01 \mathrm{mg}$ of $0_{2} / \mathrm{L}$ and automatically took the sample temperature into account. The soil temperature varied between 9 and $14{ }^{\circ} \mathrm{C}$ throughout the experiment and, for a given day, differed between different locations from 0.2 to $0.4{ }^{\circ} \mathrm{C}$ at the depth surveyed.

\section{Protocol for installing Tensionics}

After promising preliminary investigations, an experiment was conducted during the winter of 1995-1996. The soils from four peach orchards were monitored from January to early May. They corresponded to two pairs of fine- and coarse-textured soils, each pair (finetextured/coarse-textured) was planted with the same variety of peach tree grafted onto the same rootstock of the same age and at the same planting density. The finetextured soil was sandy loam consisting of recent alluvial deposits by the Rhône river and the coarse-textured soil was a very stony quaternary fluvial-glacial deposit (75\% pebbles) with a very sandy fine fraction (70\% sand). At the beginning, four Tensionics were installed in the plots with fine-textured soil and five in the plots with coarse-textured soil (these were more difficult to install). Another one was installed in all plots after 1 month because the first readings obtained were heterogeneous, as will be seen hereafter. As the roots colonised mainly the -10 - to $-50-\mathrm{cm}$ soil layer, all ceramic cups were placed at a depth of $30 \mathrm{~cm}$. Each Tensionic was marked and monitored individually.

\section{RESULTS}

In order to give an idea of the distribution and type of variability of the data collected, the whole data set is shown in figures 2 and 3. Even when taking into account the usual variability of oxygen distribution in the soils, the data of each plot for a given
CV. RED DIAMOND

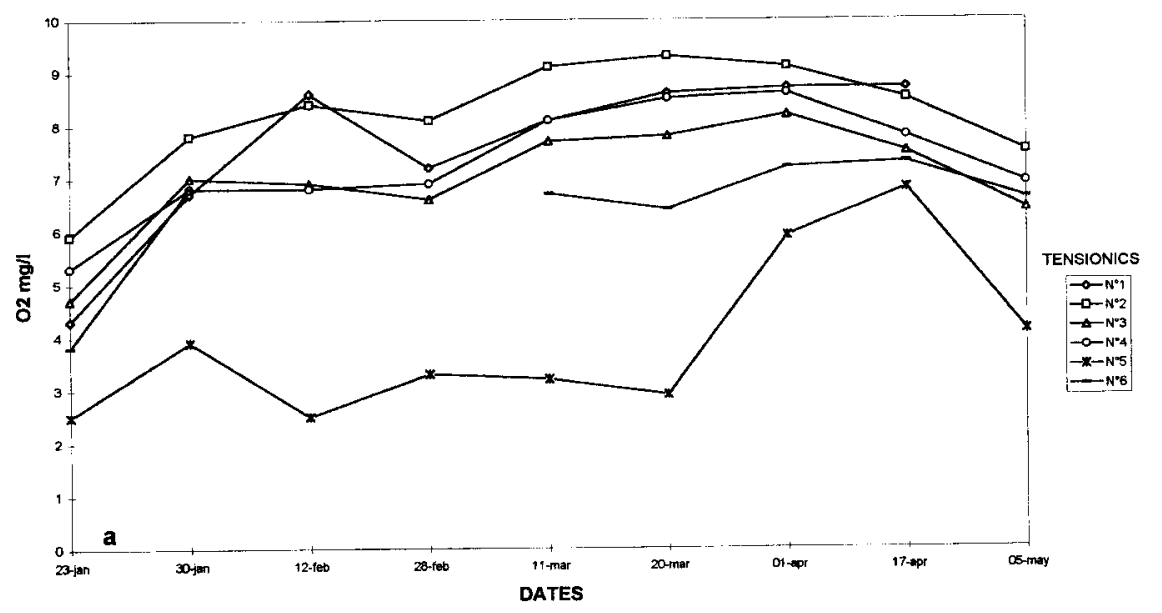

CV. RED D'AMOND

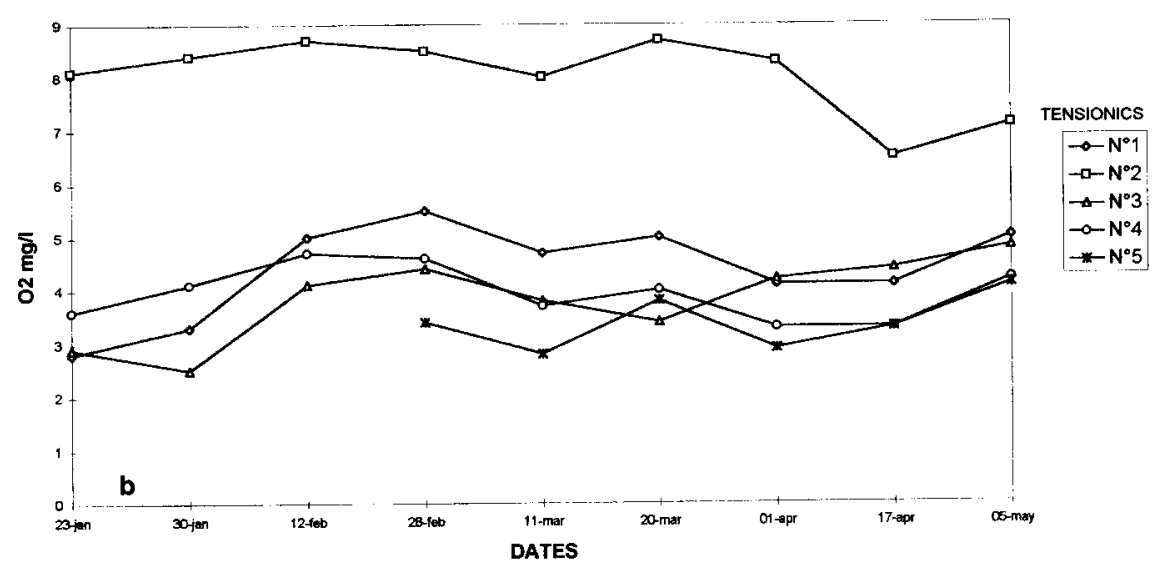

a)

b)

Fig 2. Distribution and variation of dissolved oxygen values ( $\mathrm{mg} \mathrm{O}_{2} / \mathrm{L}$ ) over the winter and spring periods, measured in the solution of two orchard soils using two sets of Tensionics. Example of cv Red Diamond. a: on coarse-textured soil, b: on fine-structured soil. 
CV. O. HENRY

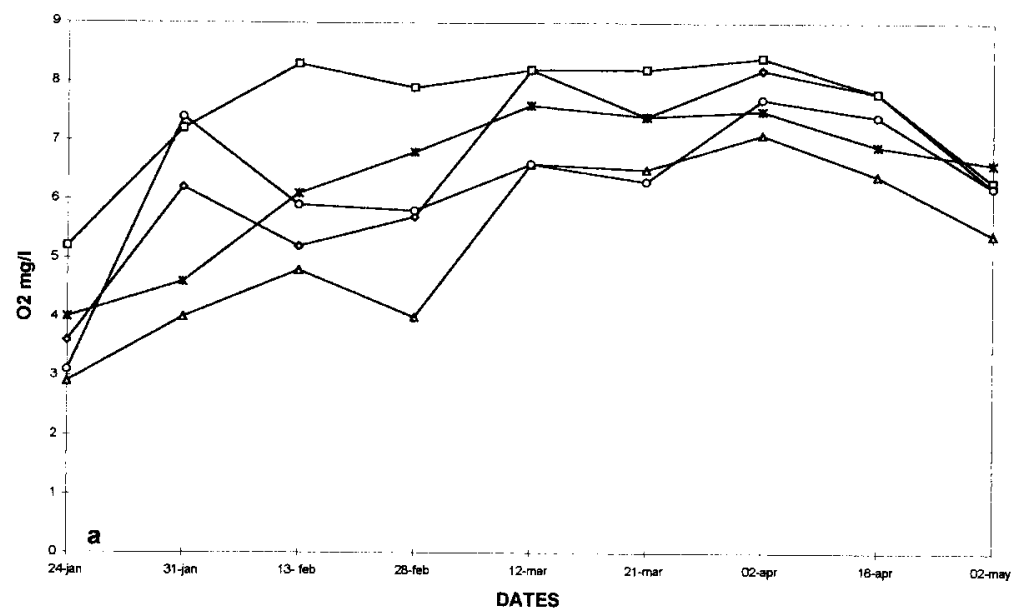

CV. O. HENRY

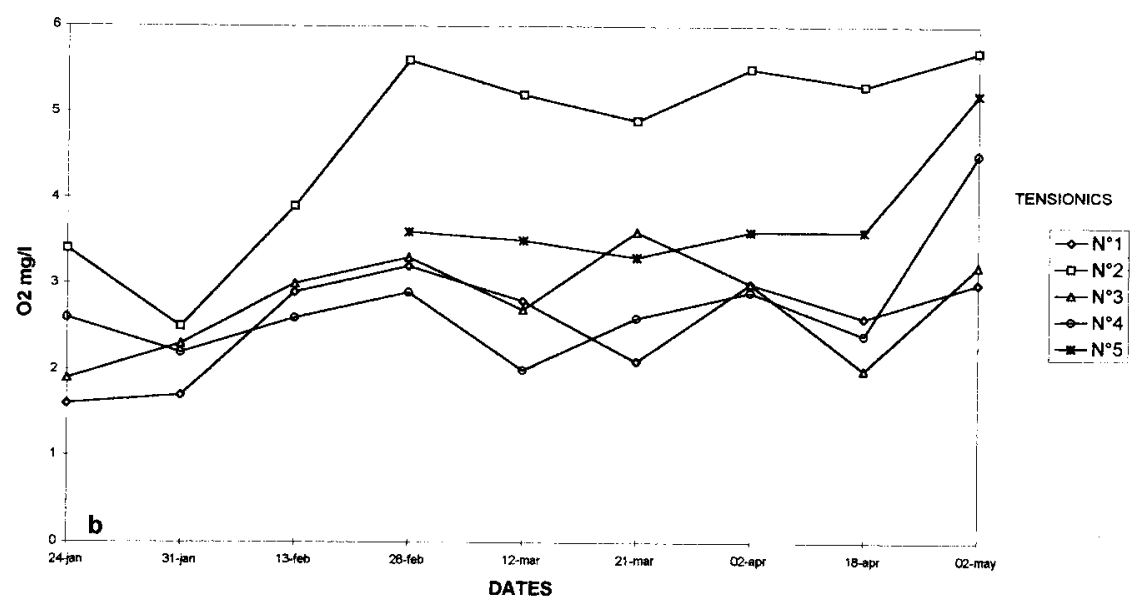

a)

TENSIONICS

b)

Fig 3. As for figure 2, with ev O Henry and two other plots on coarse or fine-textured soil. day may appear scattered. In fact a more thorough analysis shows that they are relatively grouped except one. When the Tensionics are considered individually, they exhibit the same temporal variation and the markedly different value is always obtained from the same Tensionic (ie, No 5 in the coarse-textured soil and No 2 in the fine-textured soil in the case of cv Red Diamond). Examination of the ceramic cups in situ at the end of the experiment provided a straightforward explanation for the divergent values (earthworm burrow, bundle of hair roots, clod containing a large amount of poorly decomposed organic matter). Very similar observations were made in preliminary investigations.

\section{DISCUSSION}

\section{Apparatus}

Given the precautions taken when the ceramic cups were installed and the restricted diameter of the hole required to install them, interference from the atmosphere seemed negligible and the soil was disturbed very little. The Tensionics should preferably be installed a little in advance to ensure that the equilibria that have been disturbed can be reestablished. The mud used as a seal and to ensure continuity with the soil nevertheless created a heterogeneous layer relative to the surrounding soil, 
and this could alter the conditions for gas circulation at this level. In fact, like the ceramic cup itself, this heterogeneous element probably has a limited effect on the diffusion of oxygen in its dissolved state because of the long equilibration time. The minimum time chosen, based on that determined by Moutonnet for nitrates, is somewhat arbitrary, but the differing time intervals between measurement dates did not indicate any systematic effect. However, this point requires further investigation and work is at present in progress (Bienfait and Benkhellouf, 1995). As implied above, equilibration time affects the extent to which the liquid sample in the ceramic cup is representative of the solution in the immediately surrounding soil and even of that of a certain volume of soil around it. This cumulative aspect allows the equilibration time to be considered as the 'data recording period' for the liquid. This constitutes a major advantage in estimating average conditions for root functioning, as compared with instantaneous measurements of gas. The latter are more likely to reflect heterogeneous rates of diffusion in a medium subjected to constant changes. On the other hand, a minimum soil water content is probably necessary to achieve satisfactory $\mathrm{O}_{2}$ diffusion. This point needs to be evaluated and could limit the use of this method.

In addition, the capillary tubes leading to the ceramic cup contain $1 \mathrm{~mL}$ of liquid per linear meter. Their effect is thus limited at shallow depths but is also being studied at greater depths (Bienfait and Benkhellouf, 1995).

\section{$\mathrm{O}_{2}$ measurement in the liquid sample}

The oxymeter used has a very satisfactory resolution relative to the measurable differences in the soil, and it is reliable if maintained and used in accordance with the standard procedures for this type of equipment. The use of a syringe to remove the sample from the ceramic cup avoids pollution from the atmosphere. The liquid has to be injected gently into the bottom of the collection phial. The neck of the phial is only very slightly larger than the diameter of the oxymeter probe, to keep exchanges with the atmosphere to a minimum. Moreover, the probe is inserted and moved around slowly in the liquid being examined. The phial itself also has a small internal diameter (approx $25 \mathrm{~mm}$ ) so that the head of the probe is completely covered by the liquid despite the small quantity collected and the liquid-air contact surface is reduced. There is nevertheless a contact surface between the liquid sample and the air during injection into the phial. A series of tests conducted to evaluate the level of interference revealed a noticeable increase in $\mathrm{O}_{2}\left(0.4-0.8 \mathrm{mg} \mathrm{O}_{2} / \mathrm{L}\right)$, mainly for low soil values since the difference in $\mathrm{O}_{2}$ content between soil and atmosphere is therefore higher. This aspect constitutes a major bias. It can be theoretically estimated but new procedures for collecting the sample and measuring $\mathrm{O}_{2}$ are currently being developed in order to reduce this interference.

\section{Values obtained}

It was mentioned above that the values observed in a given plot and on a given day seemed scattered but were in fact relatively grouped except one. This was true for each notation date throughout the measurement campaign and the marginal values always concerned the same sensor. The phenomenon was observed more or less clearly in each plot and a clear circumstantial explanation was found for this particular behaviour in each orchard. Under these conditions, these 'abnormal' values might complicate the task of comparing and interpreting soil conditions between plots but, on the other hand, they constitute good criteria of reliability for the method itself: the same causes systematically induce the same effects which are recorded by the Tensionics as such. In parallel, in each plot, the method provided a batch of relatively grouped values, whose mean can be considered as a reflection of the overall state of the soil. The oxygen distribution in the soil is known to be very heterogeneous. The values obtained give an idea which seems representative of this heterogeneity even for the very different examples of soils compared. Moreover, more accurate information can be easily obtained by increasing the number of sensors and by prolonging the survey since sensors are inexpensive and the experimental procedure is simple. Unfortunately, since no similar techniques for measuring soil solution oxygenation exist, there was no basis for comparison.

\section{CONCLUSION}

There is no convenient method for estimating global soil oxygenation at the scale of the root system of plants and, in particular, trees. Moreover, using the soil solution to evaluate oxygenation enables more relevant integrated values to be obtained than by using the gas analysis approach. 
The Tensionic is easy to install and enables the soil solution to be conveniently and efficiently extracted. Surveys can easily be performed over variable durations. On the other hand, the measurement of the $\mathrm{O}_{2}$ in the liquid sample has to be improved. Values obtained from well-aerated soils are fairly reliable, but the bias is large for low $\mathrm{O}_{2}$ levels and another more precise measurement system is in preparation. In fact, this last point is somewhat secondary and purely metrological. The most interesting aspect of this method is the collection of representative samples of the soil solution. The proposed device (with an adapted distribution in the studied plots) seems to fulfil this role provided that equilibration between soil and cup is correct. The time needed for equilibration and the effect of soil humidity on $\mathrm{O}_{2}$ diffusion are currently being studied. In conclusion, further improvements to the $\mathrm{O}_{2}$ measurement by more specialised scientists are needed but the principle of the system should be of value to several areas of agronomy.

Acknowledgements: We had useful discussions with D Bienfait of the Ctifl in Carpentras who is also interested in the system, and wish to thank V Valles and P Renault of the Station de sciences du sol (Inra) in Avignon and P Saglio of the Station de physiologie végétale (Inra) in Bordeaux, among others, for their advice. We also thank T Girard - Inra-SRIV, domaine de Gotheron (Valence) for his help in installing the Tensionics and carrying out some of the measurements.

\section{REFERENCES}

Bienfait D, Benkhellouf N (1995) Dépérissement du cerisier par asphyxie : approche de l'oxygène et du gaz carbonique du sol au moyen du tensionic. CR Expérimentation Cerise. Dom Exper La TapyCarpentras, 89-99

Faulkner SP, Patrick WH, Gambrell RP (1989) Field techniques for measuring wetland soil parameters. Soil Sci Soc Am J 53, 883-890

Glinsky I, Stepniewski W (1985) Soil Aeration and its Role for Plants. CRC Press, $229 \mathrm{p}$

Levy G, Toutain F (1979) Aération et phénomènes d'oxydo-réduction dans le sol. In: Pédologie. 2. Constituants et propriétés du sol (P Duchauffour, B Souchier, eds), Masson, Paris, 347-369

Moutonnet P, Pagenel JF, Fardeau JC (1993) Simultaneous field measurement of nitrate-nitrogen and matric pressure head. Soil Sci Soc Am J 57, 1458-1462

Renault P, Stengel P (1994) Modelling oxygen transport in aggregates. Soil Sci Soc Am J 58, 1017-1023

Vigouroux A, Bussi C (1994a) Influence des caractéristiques édaphiques des vergers sur la teneur en eau hivernale des tiges de pêcher. Séminaire GEA L'eau dans la vie de l'arbre, Clermont-FerrandTheix, 14-15 April

Vigouroux A, Bussi C (1994b) Une action possible des sols sur la prédisposition des pêchers au dépérissement bactérien par modification de la teneur en eau hivernale des tiges. agronomie 14, 319-326 